\title{
Statuslabilität und Protest
}

\author{
FRANZ WALTER
}

$S$ eit einigen Jahren kehren die Proteste zurück. Nur, was ist deren Charakter, was ihr Ziel? Haben wir es hier mit einer sich neu formierenden alternativen Phalanx gegen die Herrschaft des Finanzkapitalismus zu tun? Oder fügt sich nur im Blick von außen zusammen, was im Grunde höchst heterogen ist?

Der Stuttgarter Aufruhr gegen das dortige Bahnhofsprojekt S21 etwa trug rundum bürgerliche Züge, auch und gerade in seinem postmaterialistischen Kern. Vernissagen, die Oper, die Staatsgalerie gehören zum Alltag einer avancierten akademischen Mittelschichtigkeit. Der Stuttgarter Protest entsprang ganz den bürgerlichen Werten des Bewahrens und Konservierens überlieferter Lebensorte. Nahezu die Hälfte der Demonstranten verfügte über einen Hochschulabschluss; zwei Drittel waren älter als 45 Jahre. Es war eine durchaus privilegierte Schicht, die sich da über Monate im Mittleren Schlossgarten versammelte. Aus ihrer materiell gehobenen Lage machten die Akteure in Erkundungen von Sozialwissenschaftlern auch keinen Hehl. Frisch bekehrte Kritiker mit langer CDUPrägung, wie oft medial vermutet, fand man allerdings unter ihnen nur wenige. Das Gros hat keineswegs zum ersten Mal in seinem Leben gegen die Herrschenden und ihre Zustände rebelliert. Rund $80 \%$ derjenigen, die über Monate ihr „Nein“ zum neuen Bahnhof lauthals skandierten, waren schon in früheren Jahrzehnten aktiv dabei, wenn die Parole deklamiert wurde: „Wehrt euch, leistet Widerstand gegen Notstandsgesetze, Berufsverbote, Atomkraftwerke oder Raketen in diesem Land“.

Natürlich sind die Handlungsmotive weiterer Bürgerproteste gegen Flughafenausbau, Windräder und Oberleitungen - ins Auge fällt der markant reaktive, bestandsverteidigende Wesenszug der bürgerlichen Auflehnung, was revoltebereite Jugendliche infolgedessen wenig anzieht - nicht rundum altruistisch begründet, nicht allein von der selbstlosen Sorge um den Bestand an Fledermäusen, Juchtenkäfern und Bäumen angetrieben. Die umtriebigen Wortführer der diversen Initiativen sind in bemerkenswerter Zahl Eigentümer von Grundstücken und Häusern. Prosaisch formuliert: Die Immobilienwerte fallen rasant, wenn Stromleitungen und bis zu $150 \mathrm{~m}$ hohe Windräder in einem bis dahin beschaulichen Städtchen den Blick auf ein betörendes Landschaftspanorama verstellen.

Ebenfalls fällt die recht hohe Quote an Unternehmern unter den Beteiligten des Protests auf, während Arbeiter und Arbeitslose hier rare Erscheinungen sind. Ein anderer, geradezu formativer Typus der „Bürgerwehrhaftigkeit" ist der verrentete Ingenieur. Fortschrittsfeindlich ist er keineswegs, im Unterschied zu manchen Studienräten auf den Stuttgarter Kundgebungen. Er argumentiert jederzeit auf dem Level technischer Progressivität, um sich der Stromtransporttechniken, die sein Umfeld bedro- hen, mit „Fachverstand“ $z$ u entledigen. Kurzum: Es geht beim Protest um handfeste Interessen, was weder verwerflich noch gar illegitim ist, aber auch nicht als bürgergesellschaftliche Selbstlosigkeit süßlich veredelt $z u$ werden braucht.

Anders noch stellt sich die Occupy-Bewegung dar. Die Teilnehmer dort gehörten zumeist nicht zu den Altbürgern mit einer gelungenen, häufig bereits abgeschlossenen Berufsbiografie in privilegierter Stellung auf den Rängen der gesellschaftlichen Hierarchie. Sie zählten aber auch nicht zur Gruppe der Abgehängten, zur Klasse der Bildungsarmen. Im Gegenteil: In den neuen Protestbewegungen 2011 dominierten junge Leute mit Abitur und Hochschulausbildung, für die allerdings der Einstieg in eine sichere, materiell attraktive Berufslaufbahn versperrt war. Eine nachwachsende Generation innerhalb der sozialen Eliten sieht sich blockiert, steht im Prozess der sozialen Aufstiegsanstrengung vor verschlossenen Türen.

Die Soziologen reden in solchen Fällen von einer Statusinkonsistenz, also von der Diskrepanz zwischen hohem Leistungspotenzial und geringer gesellschaftlicher Position, welche die Revolte nährt. Wenn auf diese Weise die Elitenzirkulation stockt, dann bekommen soziale Ordnungen einen Gegner, der keineswegs sozial unten siedelt. Elitenrivalität und Elitendissens bilden, wie Historiker wissen, oft genug den Auftakt für weichenstellende gesellschaftliche Konflikte. Elitenzugehörige, deren eigene Wahrnehmung ihrer Werteposition nicht mit der realen gesellschaftlichen Rolle synchron läuft, vollziehen den Frontwechsel, steigen aus, üben Verrat oder wie sonst die Metaphern lauten, die man in der Literatur zur Abkehr der unzufriedenen Intelligenz vom klassischen Bürgertum zuschreibend benutzt hat. Ob sich aus der Frustration der gebildet-blockierten Nachwuchselite lediglich eine verspielte Bloggerrevolte von nöhlenden Foristen im Netz ergibt, oder ob sie zur Ausgangslage weitreichender Veränderungen wird, hängt gewiss nicht zuletzt davon ab, ob es zur schwierigen Begegnung der nach oben abgeblockten Frondeure mit einer organisierten Sozialopposition der klassischen Interessenvertretungen von unten kommt. Indes: Ein Selbstläufer waren solche Aktionssymbiosen nie.

FRANZ WALTER, Prof. Dr., lehrt Politikwissenschaft und leitet das Institut für Demokratieforschung an der Georg-August-Universität Göttingen. Arbeitsschwerpunkte: Parteienforschung, Demokratieforschung.

stine.marg@demokratie-goettingen.de 